\title{
PERKEMBANGAN DESAIN BUSANA MUSLIM DALAM TINJAUAN SOSIOLOGIS
}

\author{
Sri lka Damayanti *)
}

\begin{abstract}
Clothing is a textile craft product which contains various social meanings. The recent development of moslem clothing in Indonesia has changed significantly. The moslem clothing basic procedure is adapted flexibly and smoothly in Indonesia by adjusting to the local culture. The such condition therefore creates a moslem clothing design which then becomes a popular culture. This article analyzes the development of moslem clothing desighn through social approac by Pierre Bourdieu to see the habitus and the agent. The result of the research shows that the social enviroment habit has unconsciously influenced the trend of the moslem clothing wear and the role of public figure. From the result of the research, it can be concluded that in Indonesia has been shaped a style and moslem design clothing which has a certain unieqeness including in how it flexibly blends with the custom wear each region.
\end{abstract}

Key words: clothing, moslem, hijab, fashion, Bourdieu

\section{ABSTRAK}

Busana adalah produk kriya tekstil yang didalamnya mengandung beragam makna sosial. Perkembangan busana muslimah di Indonesia saat ini mengalami perubahan yang sangat signifikan. Kaidah berpakaian menurut Islam diadaptasi dengan luwes dan cair di Indonesia, disesuaikan dengan kultur setempat. Dari hal tersebut menghasilkan desain busana muslim yang kemudian justru menjadi kebudayaan populer. Tulisan ini membahas perkembangan desain busana muslimah dengan pendekatan sosiologi dari Pierre Bourdieu untuk melihat habitus dan agen pembawanya. Hasil penelitian ini menunjukan bahwa kebiasaan yang ada lingkungan sosial secara tidak sadar telah mempengaruhi populernya pemakaian busana muslim dan peranan publik figur sebagai pedoman gaya terkini. Dari hasil penelitian ini dapat disimpulkan bahwa di Indonesia terbentuk gaya dan desain busana muslimah yang memiliki kekhasan tersendiri termasuk dapat berbaur dengan busana adat pada tiap daerah.

Kata Kunci: Busana, muslim, hijab, fashion

* Sri Ika Damayanti (ikkada@gmail.com),Mahasiswa Pengkajian Seni Rupa Pasca Sarjana Institut Seni Indonesia 


\section{PENDAHULUAN}

Pakaian merupakan salah satu hasil karya kriya yang berkaitan erat dengan nilai-nilai sosial dan hampir selalu memiliki kepentingan dibalik unsur visualnya. Setiap lapisan masyarakat menggunakannya dan sudah tidak menjadi benda yang asing, namun selalu ada perbedaan nilai bagi setiap pemakainya. Busana dapat dimetaforakan sebagai "kulit sosial dan kulit budaya" yang dapat menunjukkan identitas pemakainya dan juga menentukan citra (Nordholt, 2005:1). Sedangkan menurut Koentjaraningrat pakaian juga merupakan suatu benda kebudayaan yang sangat penting untuk hampir semua suku bangsa di dunia. Thomas Caycle berpendapat bahwa pakaian menjadi pelambang jiwa (emblems of the soul) dan menurut Umberto Eco, "Aku berbicara lewat pakaianku" ( I speak through my cloth). Dari hal tersebut memunculkan suatu pemaknaan bahwa visualisasi busana memiliki hubungan sebab akibat dari lingkungan sosialnya yang dipengaruhi gaya personal. Selanjutnya, busana muslimah menjadi suatu yang ingin untuk dikaji lebih lanjut oleh penulis karena keberadaannya di Indonesia saat ini justru menuju fashion arus utama.

Perkembangan busana muslimah di Indonesia saat ini mengalami perubahan yang sangat signifikan. Kaidah berpakaian menurut Islam diadaptasi dengan luwes dan cair di Indonesia, disesuaikan dengan kultur setempat. Konsep berbusana untuk perempuan muslim yang mulanya berdasarkan syariat keagamaan dapat menjadi suatu trend fashion dan bahkan membentuk budaya baru. Pergerakan trend berbusana muslim pun berjalan beriringan dengan perubahan trend fashion pada umumnya. Busana muslim dan segala atribut pelengkapnya hadir dengan berbagai macam kreasi, jenis, warna, dan bahan yang justru sangat berbeda dari pusat Islam, di negara Arab. Hal tersebut membuat Indonesia menarik bagi perkembangan trend fashion muslim, sehingga ada wacana pencanangan Indonesia akan menjadi pusat kiblat trend mode dan fashion muslim dunia pada tahun 2020 pada saat konferensi pers Indonesia Fashion Week 2013.

Melihat lingkungan sekitar saat ini, semakin banyak perempuan yang mengenakan busana muslimah. Mereka mengenakannya tidak hanya di tempat yang berhubungan dengan acara keagamaan tetapi juga di ruang-ruang publik seperti sekolah, kampus, kantor, mall. Pemakai busana muslimah juga tidak identik dengan ibu-ibu bergaya kaku dengan pakaian monoton tetapi justru didominasi perempuan muda dengan gaya pakaian yang modis dan up to date. Lalu bandingkan dengan kondisi sebelum dan awal tahun 1990-an, dimana perempuan yang mengenakan busana muslimah pada kesempatan umum, meskipun ada, masih sangat jarang, terlebih bagi perempuan muda dan remaja putri.

Busana muslim, termasuk penutup kepala dan rambut bagi perempuan muslim, dianggap salah satu kewajiban yang harus dilakukan oleh muslimah. Hal tersebut menjadikan pemakai busana muslim telah merasa memiliki pencapaian tersendiri kaitannya dengan religiusitas. Namun, maraknya fashion muslim di 
Indonesia tidak sebatas fenomena yang berkaitan dengan religi, ada banyak permasalahan di dalamnya yang dapat dikaji, meliputi sosial, budaya, gaya hidup, gaya busana dan estetikanya. Ada banyak perbedaan dari busana muslim di Indonesia dengan pusat negara Islam di Arab, tentunya karena ada berbagai faktor yang mempengaruhinya. Hal tersebut memunculkan masalah bahwa visualisasi fashion muslim di Indonesia memiliki perbedaan gaya ciri khas tersendiri dan bagaimana perjalanan fashion muslim hingga sampai dalam posisi saat ini. Gairah fashion muslim di Indonesia sangat menarik penulis untuk mengkajinya lebih dalam, khususnya dalam perkembangan gaya dan desainnya dari tahun ke tahun dilihat dari sudut pandang seni, desain dan budaya.

Busana muslimah merupakan bentuk pergeseran fenomena berpakaian yang sangat menonjol dalam budaya populer di Indonesia saat ini. Menunjukan identitas muslim dengan atribut busana muslimah tidak lagi dicirikan sebagai fanatisme Islam. Gaya pakaian muslim di berbagai wilayah indonesia berbeda beda dan mempunyai karakter masing masing yang menjadikanya ciri khas daerah tertentu sesuai dengan kebudayaan dan tradisi masyarakat. Sejalan dengan perkembangan pakaian secara umum, berkembang pula gaya busana dalam kalangan muslim di Indonesia. Penerapan fashion muslim kini mengalami perkembangan, dan terjadi dalam berbagai jenis fungsi, antara lain dalam fungsi praktis pakaian muslim sehari hari, fungsi ritual budaya, fungsi ibadah. Ketiga jenis fungsi tersebut mengalami perkembanganya desainnya masingmasing.

Alasan masyarakat dalam memilih sebuah pakaian selain sebagai unsur pencitraan juga mempunyai unsur yang lain. Hasrat untuk mendapatkan pengakuan sosial yang muncul pada setiap personal, merupakan wujud pencarian identitas dalam masyarakat. Identitas ini jugalah yang membedakan setiap manusia, lingkungan sosial, termasuk juga landasan berpikir untuk bergaya. Persoalan identitas adalah mutlak dan menjadi konsep utama dalam fungsi berpakaia (Piliang, 2003:150). Pakaian memberikan kontribusi terhadap pembentukan identitas yang menjadi hal penting saat bertemu dengan komunitas sosial tertentu, gaya hidup setiap individual yang divisualkan melalui gaya berbusana, mencerminkan gaya hidup komunal yang dicitrakan melalui simbol-simbol.

Batas-batas kategori fashion muslim kini juga telah mengalami pelebaran makna. Dalam etika muslim, busana merupakan sebuah benda yang fungsi utamanya adalah sebagai alat penutup bagian-bagian tertentu dalam tubuh manusia, kemudian desain busana dan fashion memerankan fungsi sebagai elemen pembantu dalam mewujudkan busana menjadi tepat fungsi dan menambah nilai keindahan.

Tak dapat dipungkiri lagi bahwa busana muslimah yang identik dengan atribut jilbab telah menjadi bagian dari budaya populer di Indonesia seperti halnya gaya fashion yang lain. Berbusana muslim sudah diterima oleh masyarakat dan sudah dianggap sebagai hal yang biasa. Menurut Suzane Brenner, busana muslimah dengan "jilbabisasi" di kalangan muslim Indonesia 
itu sesuatu yang sangat kompleks dan dilihat sebagai peristiwa yang seratus persen modern, la beri istilah modern alternatif. Modernitas di Barat selalu diawali dan diiringi dengan sekulerisasi, sementara fenomena "jilbabisasi" di Indonesia justru kebalikannya. Perkembangan gaya dan desain busana muslimah di Indonesia, dari tahun ke tahun selalu mengalami perubahan yang signifikan. Hal tersebut terjadi pada pelaku industri maupun konsumennya, yang kemudian semakin memacu kreatifitas dalam kreasi memunculkan atribut fashion muslim yang selalu baru. Tren fashion muslim pun direspon dengan sangat baik oleh berbagai media masa sehingga mempermudah dan mempercepat perluasan tren berbusana muslim yang menjangkau hampir semua lapisan masyarakat

Busana muslim menjadi unsur kebudayaan populer di Indonesia, dan industri busana muslim berkembang pesat. Bahkan Indonesia sendiri mencanangkan ingin menjadi pusat mode busana muslim. Untuk menuju ke arah tersebut, penulisan dan pendokumentasian arsip pun penting dilakukan, penelitian dan penulisan tentang berpakaian dan atribut busana telah dilakukan oleh orang Barat sejak dulu, itulah mengapa pengulangan style fashion lebih banyak berkiblat ke barat. Fashion sendiri merupakan suatu alat penanda kebudayaan, dan bahwa masyarakat dibentuk berdasar pakaian (Barnard, 2007:71). Selalu ada korelasi dalam berpakaian dengan kebudayaan yang berlangsung dalam suatu masyarakat, maka dari itu penelitian ini perlu dilakukan untuk membaca pergeseran kebiasaan dalam berpakaian pada mayoritas perempuan muslim Indonesia.

\section{PEMBAHASAN}

\section{Habitus dan kepopuleran fashion muslim}

Dalam melihat proses busana muslim dari busana terpinggirkan menjadi fashion arus utama, menggunakan perspektif Bourdieu mengenai habitus. Habitus adalah pembiasaan sikap yang dilakukan berulang-ulang atau membuat tindakan sosial menjadi biasa (natural) sehingga muncul kebiasaan yang terlembagakan oleh anggota masyarakat dan akhirnya membentuk sebuah identitas dan kelas sosial baru. Pembiasaan berulang-ulang ini dilakukan secara sadar atau tidak sadar. Sesuai perjalanan waktu, pembiasaan ini, atau naturalisasi tindakan ini, akhirnya membentuk sebuah kultur baru, dalam waktu yang panjang karena individu atau aktor yang melakukan pembiasaan itu, menurut Bourdieu "do not know what they are doing that what they do has more meaning than they know" (tidak tahu apa yang sedang mereka lakukan, apa yang mereka lakukan itu bermakna jauh dari yang mereka sadari) (Bourdieru, 1977:79).

Ada beberapa habitus yang menjadikan fashion muslim dihargai dan mendapat posisi di atas dalam fashion di Indonesia;

1. Dukungan pemerintah pada sekolah dan instansi

Pengaruh Islam pada gaya berbusana mulai nampak sebelum kemerdekaan Indonesia, ketika pada saat itu masyarakat pribumi sudah melakukan ibadah haji dan hadirnya organisasi islam. 
Busana muslim tidak hanya sebagai penanda kereligiusan tetapi juga suatu bentuk perlawanan politis, kecenderungan tersebut terjadi hingga pada orde baru. Mulanya busana muslim hanya diterapkan di lingkungan khusus seperti sekolah islami (MI, MTS, MA dan Muhammadiyah) atau pesantren Islam.

Busana muslim telah diterima secara terbuka oleh pemerintah. Sebelumnya pada tahun 1982, Depdikbud pernah memutuskan untuk melarang siswa perempuan mengenakan kerudung ke sekolah, kemudian pada tahun 1991 pemerintah kembali mengizinkan pemakaian jilbab di sekolah dan kantor pemerintahan. Tahun 1990an awal, pada masa ini pengguna busana muslimah masih belum begitu banyak. Pemakainnya adalah orang-orang yang dianggap memang benar menenkuni dan mengerti agama, seperti guru agama Islam, seorang yang sudah menunaikan ibadah haji, santri pesantren dan siswi yang bersekolah di sekolah berbasis agama. Bagi masyarakat umum, busana muslimah dipakai hanya saat menghadiri acara keagamaan. Butik busana muslim yang ada cenderung untuk sasaran menengah kelas atas, sebagai gambaran pada masa ini harga dari busana milik ida royani mulai dari 600 ribu. Hal tersebut sesuai dengan pemakai busana muslimah yang kebanyakan perempuan yang sudah beribadah haji

Mulai tahun 2000-an hampir semua SMA negeri di Yogyakarta justru menerapkan kewajiban mengenakan busana muslimah pada saat jam pelajaran agama, kemudian hal tersebut diikuti oleh tingkat SMP juga SD. Saat ini justru ada beberapa sekolah negeri yang mewajibkan siswi muslim berjilbab tidak hanya pada mata pelajaran agama. Dari kewajiban dan kebiasaan mengenakan jilbab pada saat jam sekolah maupun kuliah menjadikan banyak perempuan mengenakan jilbab untuk kegiatan sehari-harinya. Faktor yang mempengaruhinya antara lain karena telah terbiasa berjilbab, kenyamanan, kesenangan, adanya rasa risih apabila jilbabnya pakai-lepas dan lingkungan sekitar juga melakukan hal yang sama.

2. Penerbitan media gaya hidup muslim

Faktor yang sangat berperan dalam budaya populer tentunya media massa karena melaluinya suatu budaya dapat disebarluaskan kepada massa dengan cepat. Di Indonesia tren busana muslim mendapat respon dari berbagai majalah, koran dan tabloid untuk diulas dan ditampilkan di rubrik mode. Menginjak tahun 2000, banyak majalah Islam yang bermunculan, khususnya Paras dan Muslimah majalah yang diperuntukkan untuk perempuan. Lalu pada tahun 2012 hadir Hijabella dan Laiqa yang lebih fokus pada gaya hidup dan fashion muslimah. Koran dan tabloid umum juga mengupas busana muslim tetapi lebih dilihat dari sisi fashionnya saja. Seperti pada tabloid Aura dan Kartini yang setiap minggunya selalu menampilkan busana muslim dari fashion show seorang desainer, hal tersebut dimulai tahun 2008 sebelumnya hanya menampilkan busana umum. 


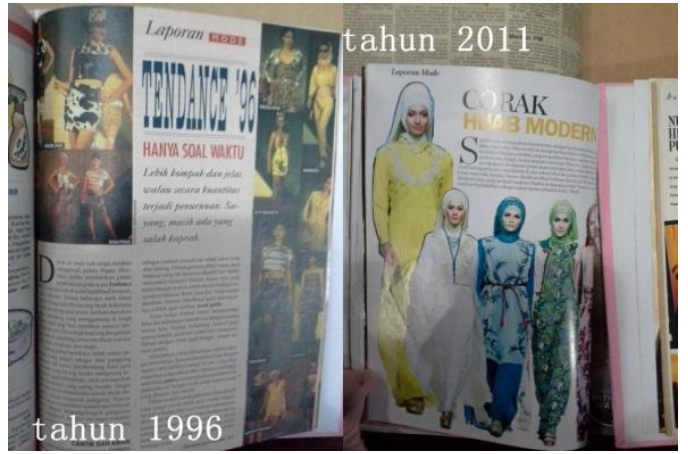

Gambar 1. Perbedaan rubrik fashion pada majalah Kartini ( Foto: Sri lka, 2014)

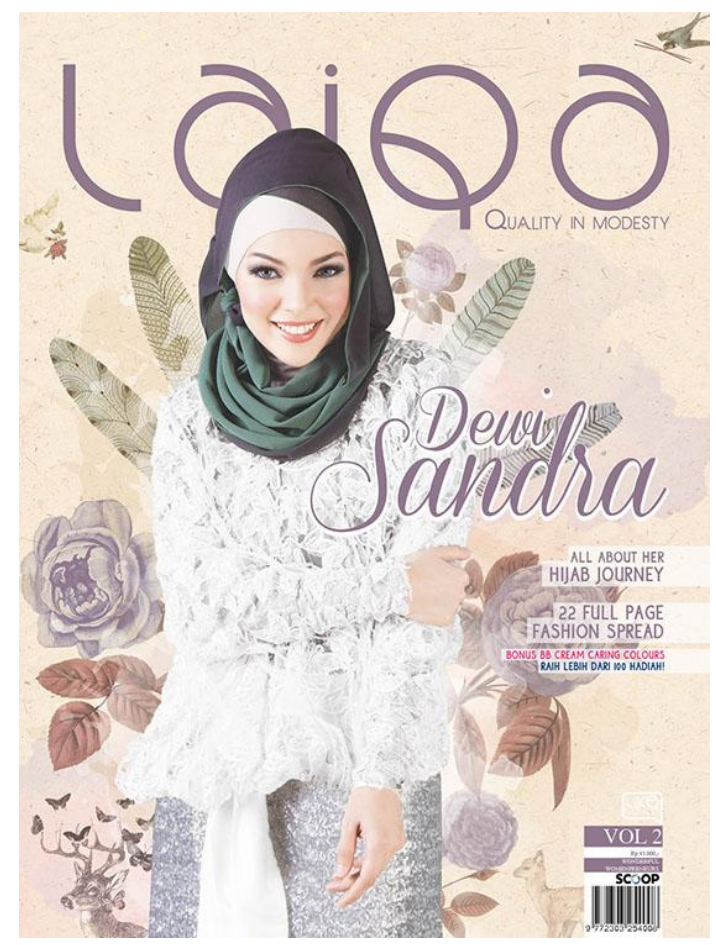

Gambar 2. Laiqa majalah gaya hidup muslimah (Foto: Sri lka, 2014)

Hal ini tentu sangat mempengaruhi posisi busana muslim karena majalah tersebut akan mengulas (serta memberi nasehat) mengenai kewajiban berbusana muslim. Selain juga ditampilkan foto-foto busana muslimah rancangan desainer yang dikenakan para model dalam bentuk fashion spread setiap edisinya. Melalui rubrik-rubrik yang ditampilkan dalam majalah, membangun citra busana muslimah menjadi sesuatu yang kekinian dan merupakan kebaikan bagi setiap muslim. Seperti halnya tagline majalah Laiqa; "Quality in modesty "Salah 1 rubrik yang selalu dihadirkan dalam majalah gaya hidup muslim adalah tutorial kreasi hijab dan tips mix and match berpakaian, hal ini bertujuan agar pembaca lebih tertarik memakai busana muslim dan membuat persepsi bahwa busana muslim bukan sesuatu yang monoton. Setiap media juga memiliki sasaran pembaca yang lebih spesifik, misalnya hijabella untuk remaja, Laiqa untuk perempuan yang mulai dewasa, dan Noor untuk ibu-ibu, dengan beragamnya media khusus gaya hidup muslim. Hadirnya media yang semakin banyak dan mengekspos kehidupan muslimah membuat para perempuan muslim merasa lebih terbiasa dengan pemakaian hijab, dan secara tidak langsung membuat perempuan yang belum berhijab memustukan untuk berhijab.

3. Kemunculan komunitas dan pengajian kelas menengah

Keberadaan hijabi fashion blogger yang sudah mulai bermuculan sejak tahun 2009 memberi kontribusi dalam inspirasi dalam memadupadankan pakaian menjadi lebih menarik. Beberapa fashion blogger tersebut adalah Ghaida Tsurruya (putri ustad Aa' Gym), Puput Utami, Siti Juwariyah, dll. Dari kumpulan fashion blogger tersebut mereka membentuk hijaber community $(\mathrm{HC})$ yang berpusat di Jakarta namun ada komunitas regional dibeberapa kota besar Indonesia, termasuk di Yogyakarta. Dari beberapa pendiri komunitas tersebut yang mulanya sekedar fashion blogger selanjutnya turut membuat clothing label busana muslim. Pada saat ini 
pula, kehadiran fashion blogger dianggap sebagai suatu ide segar dalam perkembangan gaya fashion, karena memberikan gaya berbusana inspirasional sesuai gaya mereka sendiri. Ruang gerak mereka yang berbasis dari blog dan sosial media, tentu saja berpengaruh pada segmen audiens dan pembeli produk mereka. Sasaran mereka adalah perempuan muda usia 20a-30an dari kelas menengah ke atas dan berpendidikan.

Dari komunitas, mereka sering melakukan pengajian yang cenderung untuk kelas menengah karena seringkali pengajian dilakukan di mall, butik bahkan di cafe. Pengajian dan syiar agama bagi para hijaber community sudah menembus ruang-ruang agama. Di setiap pengajian juga diadakan charity atau penggalan dana untuk amal. Pada acara-acara tersebut, peserta akan menggunakan pakaian yang modis dengan gaya hijab bermacammacam dan seringkali pula ditentukan dengan dresscode. Pengajian semacam ini juga seringkali mengundang publik figur terkenal sebagai narasumbernya. Kemudian setelah acara, mereka akan mengunggah foto-foto melalui akun sosial media seperti twitter, instagram dan blog. Kebiasaan semacam ini yang kemudian melahirkan komunitas-komunitas baru lainnya karena ada semacam perasaan keinginan melakuan hal yang sama. Melalui komunitas, akan selalu ada anggota baru, biasanya mengikuti teman yang sudah bergabung terlebih dahulu. Didalam komunitas hijaber inilah, para muslimah seolah saling memberi dukungan untuk tetap "istiqomah" dalam berhijab dan mengkampanyekan hijab sebagai sesuatu yang keren.

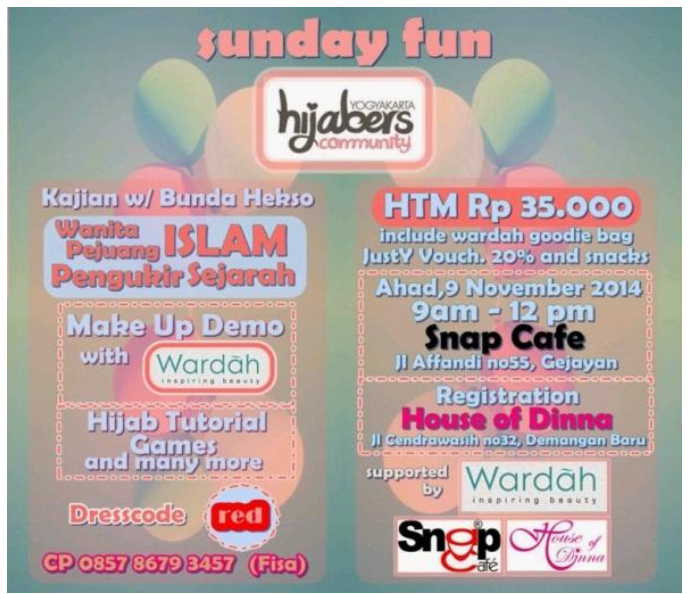

Gambar 4. Poster Pengajian Kelas Menengah yang tidak terbatas pada tempat-tempat keagamaan.

(Foto: Sri lka, 2014)

4. Tanggapnya desainer dan industri fashion

Desainer dan industri fashion telah menganggap busana muslim dapat menjadi unsur penting dari mode. Menurut Ibu Alphiana Chandrajani, desainer dan pengajar LPK Susan Budiharjo, busana Muslim akan tetap populer di Indonesia, dan ada kemungkinan Indonesia akan menjadi pusat untuk industri mode Islam. Indonesia mungkin menjadi negara yang penting untuk busana Muslim karena busana Muslim di Indonesia sangat dinamis.

Toko yang menjual jilbab dan pakaian muslim pun semakin banyak bila dulu di Yogyakarta hanya kita jumpai AlFath dan An-Nissa dengan harga menengah ke atas, sekarang telah menjamur toko yang yang lebih terjangkau seperti Ababil, Firdaus yang keduanya telah memiliki banyak cabang. Toko busana muslim paling berpengaruh di Yogyakarta adalah Karita moslem boutique, karena ia menawarkan konsep yang baru yaitu busana muslim untuk anak muda dan one stop shopping. Sedangkan desainer yang khusus 
menggeluti busana muslim antara lain Monika Jufry, Dian Pelangi, Ria Miranda, Herman Nuary, dll. Kesemuanya menciptakan busana muslim yang lebih modern dan trendi dengan ciri khas masing-masing. Jadi, toko, butik beserta desainernya sebagai bagian dari perluasan busana muslimah karena secara sederhana dapat dikatakan bahwa budaya massa adalah budaya popular yang dihasilkan melalui teknik industrial produksi massa dan dipasarkan untuk mendapatkan keuntungan kepada khalayak konsumen massa (Strinati, 2003:12)

Suatu tren diciptakan dan juga diterima dengan cepat oleh pemilik modal, e-commerce hijup.com menjadi one stop online shopping busana muslim di Indonesia. Produk yang dijual di hijup.com dari buatan tenant lokal dan desainer Indonesia. Harga yang ditawarkan di hijup beragam, dari Rp. 35.000 untuk inner hijab hingga ratusan ribu. Dari konsep hijup.com terlihat bahwa sasarannya adalah kelas menengah ke atas. Selain menjual produk,hijup.com juga memberikan tips mix and match dan mempunyai channel di youtube untuk berbagi tutorial kreasi hijab.

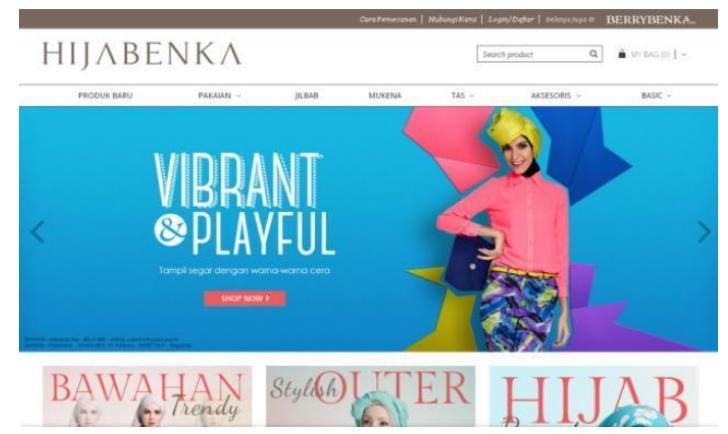

Gambar 5. E-commerce yang menyediakan berbagai macam pilihan busana muslim dari produsen lokal (Foto: Sri lka, 2014)

$\begin{array}{crr}\text { Setelah } & \text { hijup.com, } & \text { adapula } \\ \text { hijabenka.com } & \text { saudara } & \text { dari }\end{array}$

berrybenka.com, yang semula toko online yang menjual kebutuhan fashion pada umumnya. Namun karena melihat pangsa pasar busana muslim yang begitu besar di Indonesia, berrybenka.com turut membuat website online shop khusus hijab. Seperti halnya hijup.com, hijabenka juga sering membagi tips dan tutorial. Strategi seperti itu tidak hanya bertujuan untuk mengenalkan produk mereka, tapi membuat orang-orang menjadi sering melihat tren yang mereka sampaikan sehingga menjadi kebiasaan yang secara tidak sadar harus dilakukan.

\section{Agen Pembawa Fashion muslim}

1. Inneke Koesherawati

Kehadiran public figure yang mengubah penampilannya dengan jilbab, sebagai contoh paling fenomenal ialah Inneke Koesherawati. Perubahan Inneke direspon secara cepat oleh Sunsilk untuk mengiklankan varian barunya. Sunsilk hijau untuk rambut yang gatal dan berminyak di penghujung hari - yaitu rambut yang ditutup oleh kerudung dengan tagline bersih segar berkerudung. Apa yang dikenakan Inneke, dijadikan panutan oleh masyarakat. Salah satunya adalah "jilbab Inneke" yang kemudian populer. Bentuk jilbab gaya Inneke adalah memakai jilbab segitiga yang relatif kecil (tidak lebar), dililitkan ke leher, kemudian dimasukkan ke dalam kerah baju. Untuk mempermanis penampilan, bisa pula ditambahkan selembar - semacam syal - kecil dengan warna lain yang sesuai untuk dililitkan lagi di atas jilbab dasar. Gaya ini cukup lama bertahan, bahkan sampai sekarang. Para 
eksekutif muda perempuan, mahasiswi, dan ibu-ibu muda amat gemar menggunakan "gaya Inneke" ini. Saat ini Inneke menjadi brand ambasador untuk wardah, produk kosmetik buatan Indonesia yang dilabeli halal. Hal tersebut menjadi penegasan bahwa dari kemunculuan Inneke berhijab pada tahun 2000 hingga sekarang, ia masih dianggap sebagai sosok yang membawa perubahan.

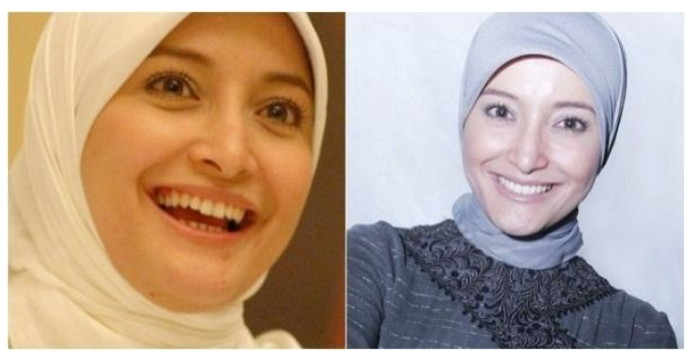

Gambar 6. Inneke Koesherawaty sebagai agen yang cukup fenomenal dalam memberi dampak pemakaian busana muslim ( Foto: Sri Ika, 2014)

\section{Dian Pelangi}

Dian Pelangi sesungguhnya adala merek dari rancangannya, namun nama itu sudah melekat pada dirirnya yang bernama asli Dian Wahyu Utami. la merupakan perancang busana yang masih muda namun sangat diperhitungkan dalam kancah fashion muslim Indonesia. Dian Pelangi merupakan salah satu tokoh yang paling berpengaruh dalam trend fashion muslim di Indonesia. Banyak masyarakat yang tampaknya mengikuti hampir setiap gaya yang diciptakan oleh Dian Pelangi. Rancangannnya menjadi sampul buku Traditional and Modern Dress in the Muslim world, Islamic Fashion terbitan Singapura. Dapat dikatakan ialah yang mengenalkan kreasi hijab untuk gaya sehari-sehari dengan sentuhan yang lebih modern. Selain sebagi perancang, dian juga blogger yang sering membagikan tipsnya dalam berbusana. Dari blog tersebut, Dian bersama-sama hijab blogger lainnya mendirikan hijaber community. Kemudian di tahun 2012, Dian juga membuat majalah gaya hidup muslim, yaitu hijabella dan menerbitkan buku sendiri dengan judul Hijab Street Style yang diterbitkan oleh Gramedia Pustaka Utama. Buku tersebut berisi mengenai 600 lebih foto muslimah dari berbagai Indonesia dan juga dari luar negeri seperti Kuala Lumpur, Singapura.

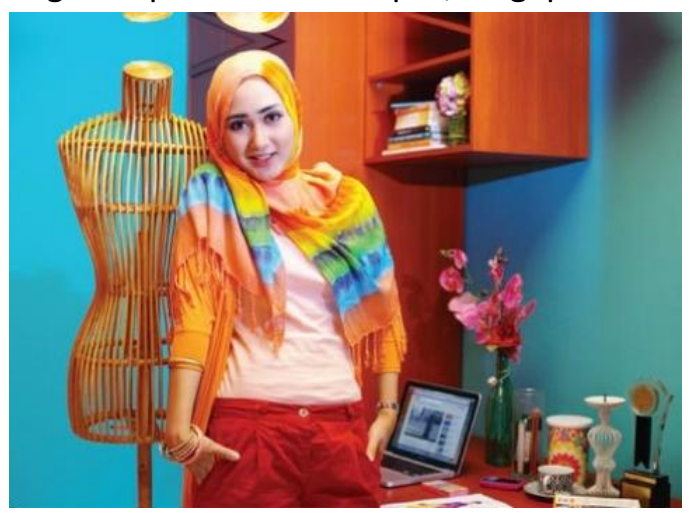

Gambar 7. Dian Pelangi, seorang desainer muda ternama sekaligus pendiri hijaber community dan penulis buku ( Foto: Sri Ika, 2015)

\section{Lyra Virna}

Lyra Virna merupakan publik figur yang belum begitu lama mengenakan hijab, namun la dengan cepat mempopulerkan hijab syra'i yang lebih fashionable. Gaya hijab syar'i fashionable. Pandangan negatif dari kalangan fanatik menimbulkan adanya gaya ini oleh para muslimah fashionable. Merupakan jawaban bahwa menggunakan busana muslimah syar'i pun masih dapat menarik. Warna jilbab bukan warna yang cerah tetapi warna-warna pastel gaya ladylike seperti dusty pink, orange nude, peach, baby blue, dan mint green. Dipadukan 
dengan busana yng berbentuk melebar dan bertumpuk-tumpuk.

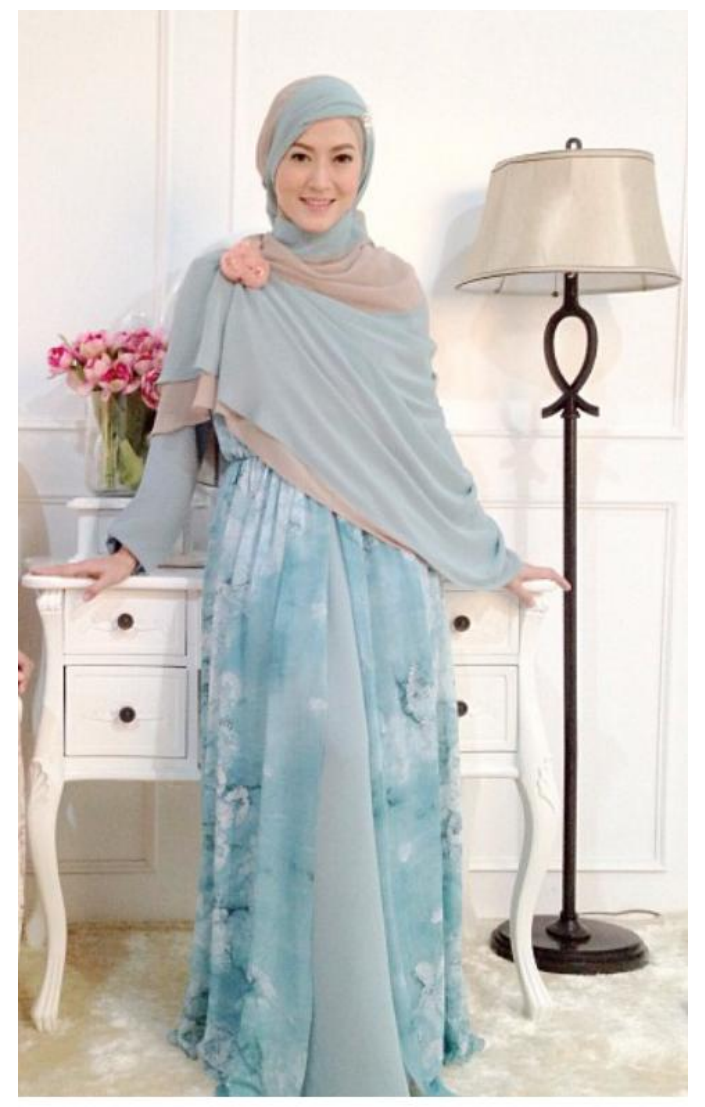

Gambar 8. Lyra Virna yang konsisten memperkenalkan hijab besar namun terlihat menarik dengan warna-warna shabby chic (Foto: Sri Ika, 2014)

\section{PENUTUP}

Seiring dengan perubahan waktu, walaupun jilbab masih menjadi simbol dari Islam, namun penafsiran terhadap makna jilbab dalam masyarakat Indonesia pun mengalami perubahan. Dahulu jilbab sangat identik dengan fanatisme Islam, penggunanya terbatas pada perempuan dengan kalangan yang tinggi tingkat religiusitasnya. Lambat laun, jilbab pun merambah ke semua lapisan masyarakat, hal ini dapat dikatakan sebagai dampak positif tetapi dapat juga dianggap negatif oleh orang-orang yang fanatik karena jilbab tidak bisa lagi diidentikkan dengan seorang perempuan yang sangat religius. Hal tersebut disebabkan karena peran mode dalam perkembangan busana muslimah yang telah mengalami banyak modifikasi. Lingkungan politik dan budaya di Indonesia yang dinamis dan toleran memperbolehkan mode Islam menjadi fashionable. Meskipun keadaan ini tidak begitu disukai dan disetujui oleh aliran Islam fanatik karena populerisasi mmerupakan hal baru bagi mereka. Namun karena itulah gaya berpakaian muslimah di Indonesia memiliki kekhasan tersendiri yang tidak serta merta meninggalkan kebudayaan aslinya.

\section{KEPUSTAKAAN}

Alatas, Alwi. 2010. "Kasus Jilbab di SekolahSekolah Negerei di Indonesia Tahun 1982-1991", http://maaini.wordpress.com/

Barnard, Malcolm. 2009. Fashion Sebagai Komunikasi,. Yogyakarta: Jalasutra.

Forshee, Jill. 2006. Culture and Customs in Indonesia. USA: Greenwood Press.

Heryanto, Ariel. 2008. Popular Culture in Indonesia, /t.k/: Taylor \& Francis Routledge.

Ibrahim, Idi Subandy (ed.). 2006. Lifestyle Ectassy: Kebudayaan Pop dalam Masyarakat Komoditas Indonesia. Yogyakarta: Jalasutra. 
Jones, Carla Fashion and Faith in Urban Indonesia dalam Jurnal Fashion Theory. Volume 11. Berg: 2007

Juneman. 2012. Psychology of Fashion; Fenomena Perempuan (Melepas) Jilbab. Yogyakarta: LkiS

Nordholt, Henk Schulte. 2005. Outward Appreances; Trend, Identitas, dan Kepentingan. Yogyakarta: LKiS

Pendergast, Sara and Tom Pendergast. 2004. Fashion, Costume and Culture. United States: Gale.

Strinati, Dominic. 2003. Popular Culture:Pengatar Menuju Budaya Populer. Yogyakarta: Bentang Budaya.

Walker, John A., 2005. Desain, Sejarah, dan Budaya; Sebuah Pengantar Komprehensif. Yogyakarta: Jalasutra. 